\title{
Effect of an Educational Program on Nurses'Knowledge and Practice Regarding management of Diabetic Crisis in the Emergency Medical Unit at Assiut University Hospital.
}

\author{
Mogedda Mohamed Mehany. \\ Lecturer of Critical Care Nursing, Faculty of Nursing, Assuit University, Egypt.
}

\begin{abstract}
Diabetic crisis is life threatening complications of Diabetes mellitus. The nurse plays a vital role in the efforts to resuscitate these types of patients., the nursing staff are in need for continuous education. the Aim of the present study was to evaluate the effect of implementing an educational program on knowledge and practice of critical care nurses regarding diabetic crisis .Method A convenient sample of all nurses working in the Emergency Medical Unit at Assuit university hospital .A structured interview questionnaire sheet and observational check list tools used to collect the data .Results the present study revealed that total scores of the nurses' knowledge and practice were improved from a pre-program level of $(18.060 \pm 3.76)$ for knowledge and (20.08 \pm 0.34$)$ for practice to an immediate post of (49.766 \pm 2.99$)$ for knowledge and $(44.7 \pm 0.05)$ for practice. However the mean scores of total knowledge and practice have decline in the follow up phase, it still statically significant higher than the pre -program level Conclusion The educational program for nurses was significantly upgrading their knowledge and practice concerning diabetic crisis . Recommendation -Orientation program should be utilized for newly graduated nurses. Nurses in these types of units should upgrading their knowledge and practice through frequent attending seminars, and conferences.
\end{abstract}

\section{Key Word: Educational Program, Knowledge, Practice \& Diabetic Crisis.}

\section{Introduction}

Diabetes mellitus (DM)is one of the most prevalent chronic disease .Diabetes affect s approximately 285 million people world wide today with the number expected to rise to 438 million by 2030 .If diabetes is not well controlled it can not only cause long -term complication ,but can also present as a medical emergency (acute complications of diabetes(diabetic crisis) include diabetic ketoacidosis (DKA), hyperosmolar hyperglycemic nonketotic syndrome(HHNNS), and hypoglycemia).Patients with these emergency(diabetic crisis DC) usually present in the emergency department and require hospitalization and admission to an intensive care units (Kaplow,\& Hardin, 2007, CDC, 2009, IDF 2009 \& Oskouie, et al., 2013)

Diabetic crisis (DC) is life threatening complications of Diabetes mellitus and c

consider the most serious acute complication of diabetes mellitus .DC responsible for more than 500, 000 hospital day per year(Kim, 2007, National Center for Health Statistics, 2009 \& Urden et al., 2012) .Recent epidemiological studies stated that the hospitalization of DC are increasing in the decade from 1996 to 2006 there was $35 \%$ increase in the number of cases .Most of patients with DC were between 18 and 44 ;years ,and half of all deaths in diabetic patients younger than 24 year.(Wolfsdorf et al., 2006, White, 2010 \& Wild et al., 2004).
A basic knowledge of pathophysiology of DC is needed to be able to recognize symptoms and understand management of DC. Nurses must be able to clinically ; differentiate between types, causes, S\&S and care of DC. (Cherlene, et al., 2013, Morton \& Fontaine, 2013) .

The nurse plays a vital role in the efforts to resuscitate the patients.The nurse is often the one who first assesses the patient initiates the emergency care and call the medical team. Nursing care is critical to the prevention of complications .The patient must be closely monitored and measures taken on correct the identified abnormality(Kaplow \& Hardin, 2007).Nursing care of patients with DC focus on early detection of signs \&symptoms ,monitoring fluid, electrolytes ,hydration status as well as blood glucose level , administration fluid ,insulin and other medications and prevention of other complications. The nurse documents patients, laboratory values and frequent changes in fluid \& medications that are prescribed and monitor the patients response. (Smeltzer et al., 2008).

For improving the standards of patients care, the nursing staff are in need for continuous education . Continuing education is one way of closing the gap between an increasing health care knowledge. rapid technology ,changes in medical practice and application on clinical practice of nurses .The educational program is considered to be an important 
means to provide nurses with theoretical and technical information needed to acquire skills and competencies necessary to continually improve nursing practice .It helps them to accept responsibility for their professional practice (Oermann,et al., 2011 \& Neeraje, 2003)

\section{Significance of the study}

Diabetes mellitus is a major world wide problem with tremendous clinical and public health burden .More than 150 million adult persons are affected world wide and the number is expected to be doubled in the next 25 years .In Egypt theWorld Health Organization( $\mathrm{WHO}$ ) reported that $5 \%-9.9 \%$ of total population have diabetes, by the 2030 it is estimated to be increased to 6.7 million diabetic patients in Egypt (Ali, 2011).In Assiut University Hospital(AUH) it was found that (450) patient with diabetes admitted to Emergency Medical Unit(medical record) . Nurses are an interral part of the emergency health team and hence the nurses are expected to provide the emergency care .So the emergency nurses are in needed to continuous updating and improving their knowledge and practice regarding diabetic crisis .So it hoped that an educational program would improve knowledge and practice of the nurses to be reflected upon patient progress .

\section{Aim of the study}

The present study aimed to:

To evaluate the effect of implementing an educational program on knowledge and practice of critical care nurses regarding diabetic crisis .

\section{Study hypothesis}

Educational program about management of diabetic crisis can significantly improve both knowledge and practice of the nurses working in emergency medical unit at Assuit University Hospitals .

\section{Subject \& Methods}

\section{Study design}

Aquasi-experimental research design with one group pre-test post -test was used in this study.

\section{Study variables}

-The independent variable is the educational program.

-The dependent variables are the nurses' knowledge and skills .

\section{Setting}

This study was conducted in the Emergency Medical Unit at Assuit university hospital .

\section{Subject}

A convenience sample of thirty nurses working in the above mentioned selected setting .

Tools: Two tools were used in this study.
First tool: Knowledge assessment tool this tool was developed by the researcher after reviewing pertinent literature to assess the knowledge level of critical care nurses regarding management of diabetic crisis which include two sections:

Section one :demographic characteristics of the nurses as age ,sex ,marital status ,qualification ,years of experience and attendance of previous training program in DC .

Section two: questions regarding definition, causes ,signs \&symptoms and emergency nursing care of the diabetic crisis in relation to three main topics which are (management of hypoglycemia ,DKA, and HHNNS), nurses response were checked with model answer and given points, this points were summed up and converted into percent score.A total score less than $60 \%$ was consider poor ( unsatisfactory level of knowledge). While $60 \%$ or more from total score was considered as satisfactory level of knowledge which subgroup into(64-60\% fair ,74-65\% good 8475 very good and $85 \%$ or more was consider excellent Second Tool: skills assessment tool the nursing practice observational check list this tool was developed by the researcher after reviewing pertinent literature to assess the performance level of critical care nurses regarding management of diabetic crisis which include urine analysis for sugar and acetone, blood sugar, ECG ,S.C.injection, infusion pump and appling care about diabetic crisis in clinical area. The observed practice was compared with standard procedures .Accordingly the nurses had one mark if the step was correctly, and zero if incorrectly done or not done .The marks were summed up and converted into percent score. A total score less than $60 \%$ was consider poor( unsatisfactory level of practice). While $60 \%$ or more from total score was considered as satisfactory level of practice which subgroup into(64$60 \%$ fair ,74-65\% good 84-75 very good and $85 \%$ or more was consider excellent .

\section{Methods}

- An official permission to conduct the study was obtained from the hospital responsible authorities in the Emergency Medical Unit after explaining the aim and the nature of the study.

- An approval was obtained from the local ethical committee and the study was followed the common ethical principles in clinical research.

- The tools used in this study were developed by the researcher based on reviewing the relevant literature.

- Content validity :the tools were tested for content validity by jury of 5 experts in the field of critical care nursing and critical care medicine from Assiut University Hospital, and the necessary modification were done. 
- The reliability was test for tool one (Knowledge assessment tool ), and tool two

- (skills assessment tool ) by using Cronbach,s coaefficient alph ( $\mathrm{r}=0.815,0.795$ respectively).

- A pilot study was conducted on 5 nurses to test the feasibility and applicability of the tools.

- Protection of the human rights (ethical considerations):informed consent was obtained from each nurse.The researcher emphasized that the participation is voluntary and the confidentiality and anonymity of the nurses will be assured through coding the data.The nurses were assured that they can withdraw from the study at any time without any rational.

The study was implemented through 4 phases;

Assessment: upon finalization of the tools and getting official permission the researcher stated to assess nurses knowledge by using self administered questionnaire sheet, this was followed by observing their practice in different shift using the observational checklist.

Planning: based on analysis of the collected data and using perttinent literature the researcher developed an educational program in form of hand out booklet in Arabic language .The objective of the program was to improve nurses' knowledge and practice regarding emergency care of patients with diabetic crisis .The program was developed to cover all necessary knowledge and practice needed for proper practice .

Implement ion: implementation of the educational program took four weeks. The program was applied for all nurses working in emergency medicine unit ,It was not applicable for all nurses attend an educational session at the same time ,so they were divided into groups 3-5 according to their work schedule. The program cover 2 parts

- Theoretical part which include

- a-first session last for (30 min). include;

- anatomy, function of the pancreas and normal blood sugar.

- Short note about diabetis in general .

- b-Second session last for (1 hour) which include:

- defination ,causes, sings \&symptoms \& emergency nursing care of hypoglycemia.

- c-third session last for(1 hour ) which include,

- defination ,causes ,sings \&symptoms \& emergency nursing care of (D K A).

- d-Forth session last for(1 hour ) which include,

- defination ,causes, sings \&symptoms \& emergency nursing care of HHNNS.

Practical part include

- Urine analysis for sugar and acetone.

- blood analysis for sugar.

- Infusion pump and S.C injection
- ECG.

- apply care of diabetic crisis in clinical area

- In these session (practical part) which lasted for 2 hours each nurse demonstrates and re-demonstrates the step of each procedure individually under supervision of the researcher .

\section{Learning environment}

The program was applied in a classroom of the emergency medical unit .

Teaching methods:

Lectures, brain storming ,discussion ,demonstration and redemonsration.

Media used :hand out ,poster ,and demonstration equipment .

Evaluation phase: each nurse was evaluated three time before, immediately after the program implementation (post test) and 3 months after the program implementation (follow up) and these were compare to pre -test level by using the same pre -test study tools (knowledge sheet and observational checklist).

\section{Statistical analysis of the data}

The collected data were coded and entered in a data based file using the excel program for windows. Frequency analysis and manual revision were used to detect any errors . Statistical analysis was performed using the software program package SPSS, version 13.Values are expressed as mean+-standard deviation or as percentages of the group from which they were derived .Independent sample t-test was used to compare the values of the mean score between the study group .The critical value of the tests(p)was considered statistically significant when $\mathrm{P}$ less than 0.05 . 


\section{Results}

Table(1): Sociodemographic Characteristics Of The Studied Sample (N0:30).

\begin{tabular}{|c|c|c|}
\hline Nurses Characteristics & No. & $\%$ \\
\hline \multicolumn{3}{|l|}{ Age } \\
\hline 20-24years old & 18 & 60.0 \\
\hline $24-30$ years old & 10 & 30.0 \\
\hline+30 & 2 & 10.0 \\
\hline $\mathrm{M} \pm \mathrm{SD}$ & \multicolumn{2}{|c|}{$24.300 \pm 2.961$} \\
\hline \multicolumn{3}{|l|}{ Sex } \\
\hline Male & 8 & 26.37 \\
\hline Female & 22 & 73.33 \\
\hline \multicolumn{3}{|l|}{ Qualification } \\
\hline Diploma secondary nursing & 18 & 60.0 \\
\hline Technical institute of nursing & 12 & 40.0 \\
\hline \multicolumn{3}{|l|}{ Years of experience } \\
\hline $\mathrm{M} \pm \mathrm{SD}$ & \multicolumn{2}{|c|}{$5.10 \pm .396$} \\
\hline $1-4$ & 18 & 60.0 \\
\hline $5-9$ & 10 & 33,3 \\
\hline $10-15$ & 2 & 6.7 \\
\hline \multicolumn{3}{|l|}{ Attendance of previous training program. } \\
\hline YES & 4 & 13.33 \\
\hline No & 26 & 86.67 \\
\hline \multicolumn{3}{|l|}{ Marital status } \\
\hline Single & 20 & 66.67 \\
\hline Married & 10 & 33.33 \\
\hline
\end{tabular}

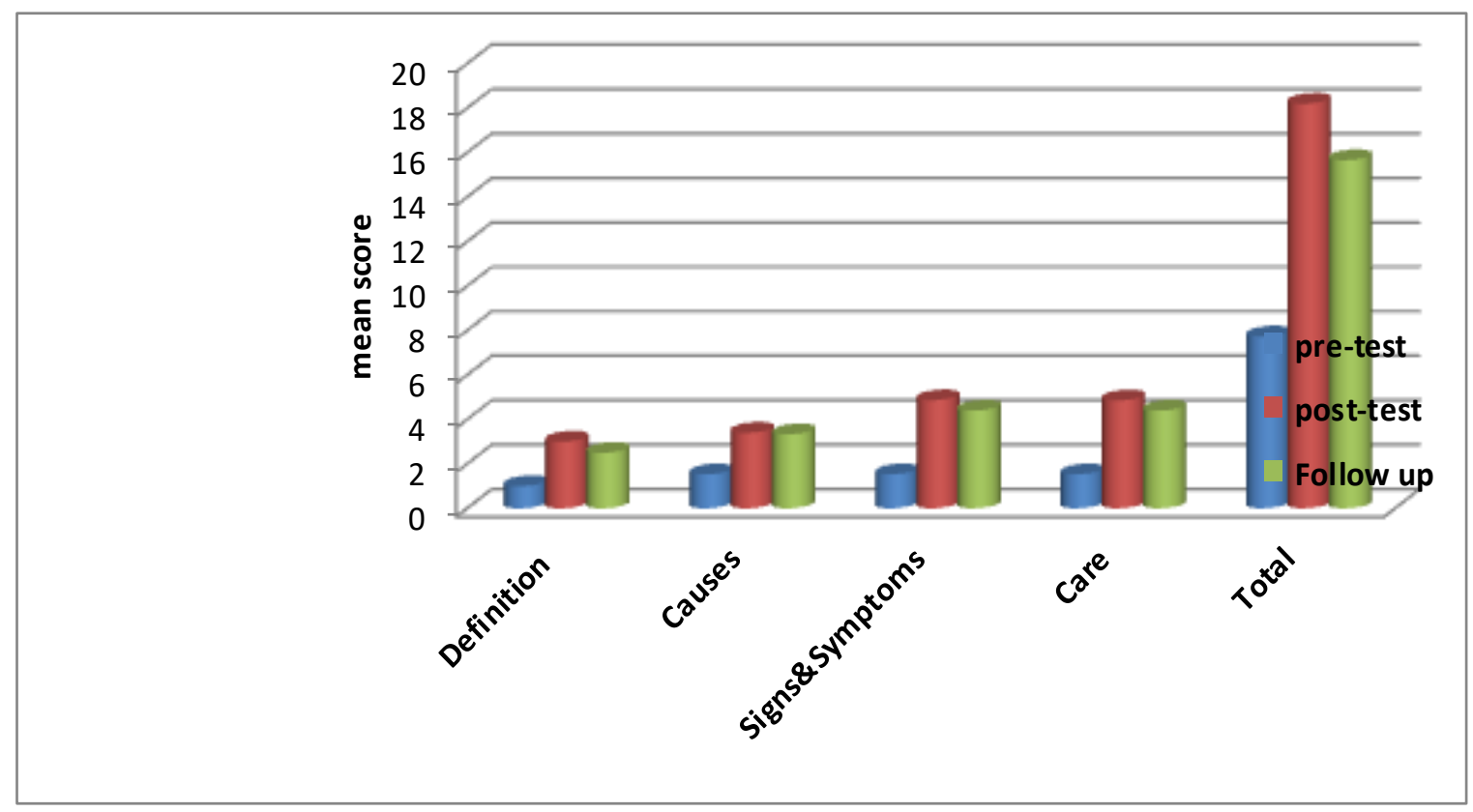

Figure (1): Mean Scores Of Nurses' Knowledge Regarding Management Of Hypoglycemia Before and After Program Implementation. 


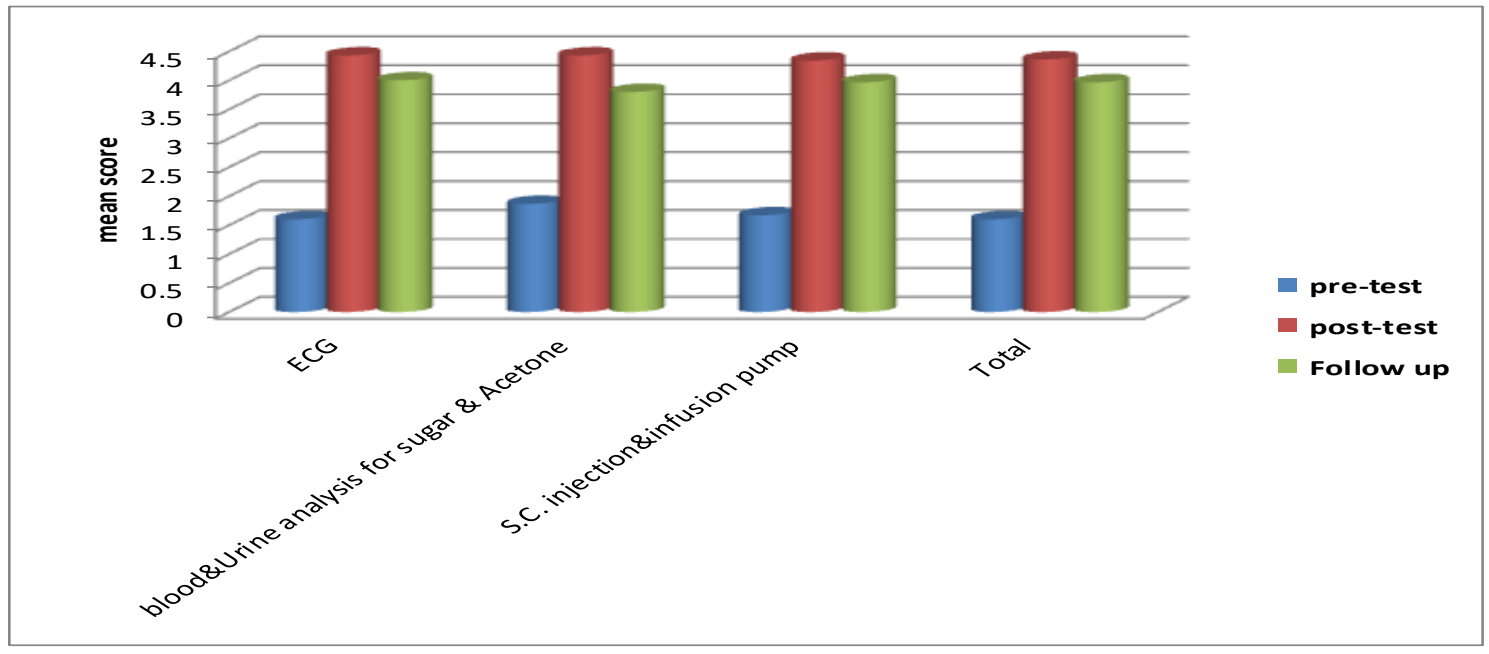

Figure (2): Mean Scores Of Nurses' Knowledge Regarding Management of Dka Before and After Program

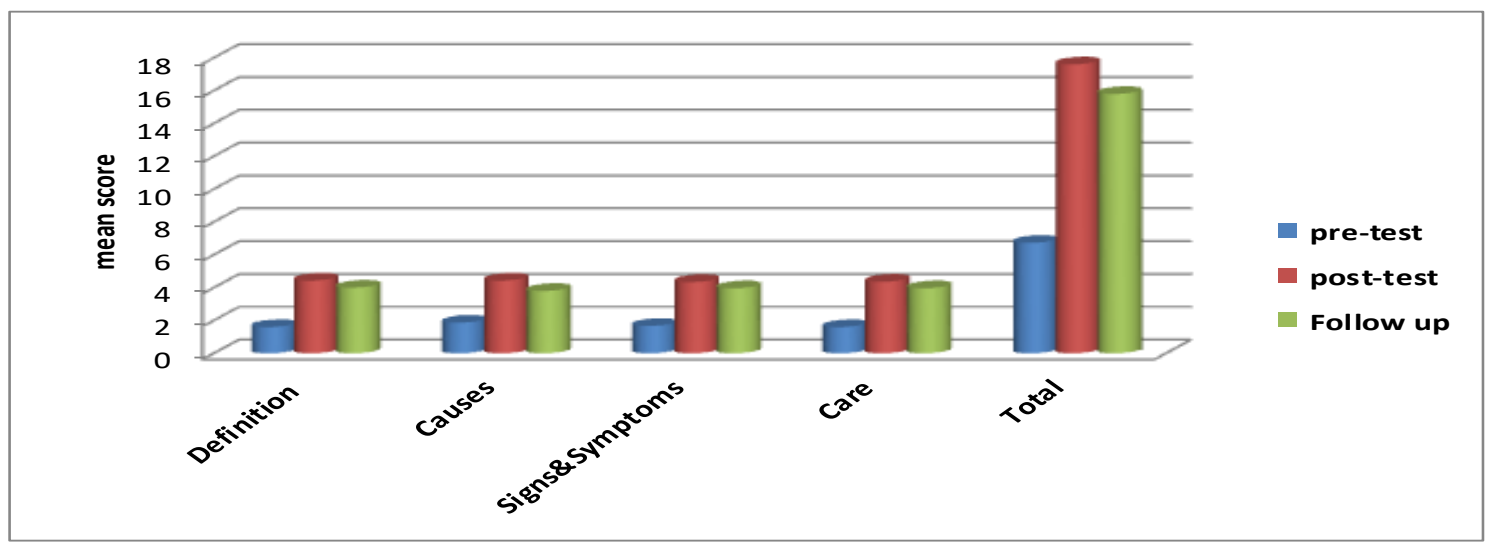

Figure (3): Mean Scores Of Nurses' Knowledge Regarding Management of Hhnns Before and After Program

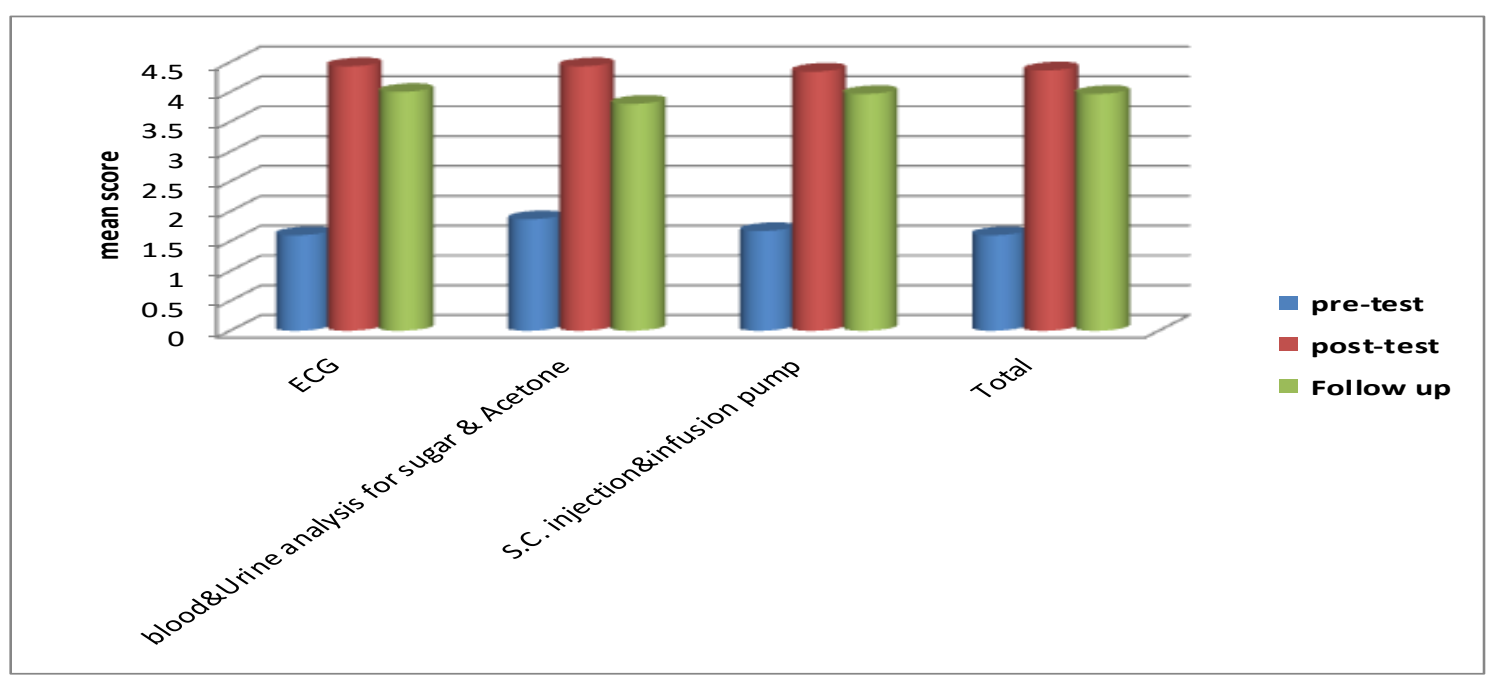

Figure (4):Mean Scores Of Nurses' Practice Before \& After Program Implementation. 
Table (2): Total Scores Of Nurses' Knowledge \&Nurses' Practice Before And After Educational Program.

\begin{tabular}{|l|c|c|c|c|c|c|}
\hline Level of satisfaction & $\begin{array}{c}\text { Pre nurses } \\
\text { knowledge(NK) } *\end{array}$ & $\begin{array}{c}\text { Pre nurses } \\
\text { practice (NP) ** }\end{array}$ & Post (NK) & Post (NP) & $\begin{array}{c}\text { Follow } \\
\text { up(Nk) }\end{array}$ & $\begin{array}{c}\text { Follow up } \\
(\text { Np) }\end{array}$ \\
\hline $\begin{array}{l}\text { Less than 60\% } \\
\text { (poor) }\end{array}$ & $30(100 \%)$ & $30(100)$ & - & - & - & - \\
\hline 60-64 (fair) & - & - & - & - & - & - \\
\hline 65-74 (good) & - & - & - & - & - & - \\
\hline $75-84$ (very good) & - & - & $4(13.3)$ & $7(23.3 \%)$ & $27(90 \%)$ & $26(86.6 \%)$ \\
\hline $\begin{array}{l}\text { More than 85 } \\
\text { (excellent) }\end{array}$ & - & - & $26(86.7 \%)$ & $23(76.7 \%)$ & $3(10 \%)$ & $4(13.4 \%)$ \\
\hline
\end{tabular}

*(NK) Nurses knowledge.

**(NP)Nurses practice.

Table(3): Relation Between Mean Scores Of Total Knowledge and Qualification\& Years Of Experience of The Study Sample.

\begin{tabular}{|c|c|c|c|c|}
\hline \multirow{3}{*}{ Items } & \multicolumn{4}{|c|}{ Total Knowledge } \\
\hline & \multicolumn{2}{|c|}{ Before } & \multicolumn{2}{|c|}{ After 3 Months (Follow up) } \\
\hline & Mean \pm SD & p-value & Mean \pm SD & p-value \\
\hline \multicolumn{5}{|c|}{ 1-Qualifications } \\
\hline Diploma & $18.611+-3.66$ & 0.085 & $44.388+-1.974$ & 0.09 \\
\hline Technical & $15.916+-3.55$ & 0.032 & $44.5+-1.243$ & 0.06 \\
\hline \multicolumn{5}{|c|}{ 2-Years of experience } \\
\hline less than 5 & $16.27+-3.313$ & 0.167 & $44.22+-1.262$ & 0.1 \\
\hline $5-9$ & $19.2+-4.315$ & 0.267 & $44.4+-2.065$ & 0.07 \\
\hline More than 9 & $19.5+-0.707$ & 0.176 & $45.5+-2.121$ & 0.08 \\
\hline
\end{tabular}

Table(4) Relation Between Mean Scores Of Total Practice \& Qualification\& Years of Experience of The Study Sample.

\begin{tabular}{|l|c|c|c|c|}
\hline \multirow{2}{*}{ Items } & \multicolumn{4}{|c|}{ Total Practice } \\
\cline { 2 - 5 } & \multicolumn{2}{|c|}{ Before } & \multicolumn{1}{c|}{ After 3 Months (Follow up) } \\
\cline { 2 - 5 } & Mean + SD & p-value & Mean + SD & p-value \\
\hline 1-Qualifications & $19.611 \pm 4.66$ & 0.329 & $40.98 \pm 3.174$ & 0.19 \\
\hline Diploma & $21.816 \pm 9.55$ & 0.396 & $40.45 \pm .273$ & 0.56 \\
\hline Technical & $20.98 \pm 0.456$ & 0.261 & $41.422 \pm 3.262$ & 0.11 \\
\hline 2-Years of experience & $19.2 \pm 4.315$ & 0.502 & $39.9 \pm 4.165$ & 0.27 \\
\hline less than 5 & $21.58 \pm 0.507$ & 0.233 & $40.8 \pm 3.431$ & 0.51 \\
\hline 5-9 & & & \\
\hline More than10 & \multicolumn{5}{|c|}{} \\
\hline
\end{tabular}

Table (1): this table show socio-demographic characteristics of the study sample.It was found that more than half of the nurses their age ranged between 20-24years with $\mathrm{M}+\mathrm{SD}(24.30+2.961)$. While the majority of them were females .More half of the studied nurses had diploma secondary nursing school (60\%)and their years of experience ranged between 1-5 year. Moreover most of the nurses had not received any previous training in the area of diabetic crisis.

Figures (1,2,3): :show mean scores of nurses knowledge concerning DC before and after implementation of an educational program .It was apparent from these figures that mean scores of the nurses knowledge in the immediate post test was higher than the pre test mean scores, while mean scores of the nurses knowledge at 3 months follow up slightly declined, it was found from these figures their were a statistically significant improvement were noticed in nurses ' knowledge between pre test scores and immediate post test scores and between pre test and follow up test scores.

Figure (4): this figure showed mean scores of nurses' practice concerning diabetic crisis before and after implementation of the educational program. It was 
noticed from this figure that mean scores of nurses practice in the immediate post test was significantly higher than the pre test mean scores. While the mean scores at 3 months follow up mildly decrease ,also table 5 pointed to statistically significant improvement in the all items of nurses practice after implementation of the educational program.

Table (2): this table show state of nurses' knowledge and practice before and after implementation of the educational program, this table displays a sharp satisfactory significant rise of nurses' knowledge and nurses' practice from pre program level to a post program level.Although the mean score of the total knowledge and practice had decline in the follow up phase, it still significant higher than the pre program level.

Table (3\&4): these tables show relation between mean scores of the total knowledge and practice of the nurses and their qualification, year of experiences. The study findings revealed that no statistically significant differences could be demonstrated between knowledge or practice's scores and nurses' qualification and years of experiences.

\section{Discussion}

Diabetic crisis considered from serious complication of diabetes mellitus(Cherlene, et al., 2013) .DC can rapidly develop causing serious threat to the patients well being (Kitabehi et al., 2010 \& Morton \& Fontaine, 2013). The nurses is often the one who first assess the patient, initiates emergency care and calls the medical team .So the nursing staff are in needed for continuous training to improve the standards of the patients care .Educational programs are considered a mean for providing nurses with theoretical and technical information needed to acquired new skill and to continually improve nursing practice (Guilbert, 1999)

In the present study the majority of the studied nurses were in the age group (20-24years),more than half of them had less than 5 years of experience and two thirds of them were single. This results be may attributed to the policy of Assuit university hospital recruitment of newly graduated nurses in the Emergency medical unit,This group of young nurses physically able to tolerate with hard work of emergency unit .This result was strongly supported by Masoud (2006) \& Gadallah, et al., (2009). While this result disagree by $\operatorname{Ganam(2011)}$ who stated that majority of the nurses were married, aged from 30 40 years and nearly half of them had experience of more than 10 years .Moreover only four nurses in the current study had previous training in the area of diabetic crisis . This mean that nearly all the nurses were not well prepared before starting their work and they got their experience through out their working in the Emergency unit.

This result was in agreement with Cannon et al., (2001) \& Hafez, (2011) (who stated most of the nurses did not receive any special education before program.

It was found from the present study that nurses had poor knowledge and practice in all items of diabetic crisis before implementation of the educational program, this was indicated by their low mean knowledges scores. This lack of knowledge and practice would have a negative impact on the nursing care provided to the patients. This poor knowledge and practice which were noticed among nurses may be attributed to the fact that nurses after graduation and before working in the Emergency medical units had not well prepared and had not attended any training courses about diabetic crisis , another possible cause nurses neglect updating their professional knowledge and practice due to lack of Arabic nursing text book and they overloaded by their work. This result was in line with Ali, (2011), who mentioned that lack of nurses information about disease nature, causes ,S\&S, and management may lead to increase incidence of complications. Also, AlKhaled et al., (2011) mentioned that general knowledge of their study nurses were moderate ,this could be explained by the lack of training for nurses ,lack of written procedure in ICU and inadequate supervisions and guidance by the nurses supervision. Also this present finding was in line with Mamum \& Lim, (2005), Mohamed \& Abdel Hammed (2012) \& Taha \& Ali (2013).

Moreover after implementation of the educational program statistically significant improvement was shown in nurses' knowledge regarding all aspects of the program ,similar improvements were also revealed in the nurses' practice. Although the follow up scores (after 3 months )had shown some decline they were still significantly higher compared to preprogram level.This decline in the total mean scores of nurses' knowledge and practice in the follow up phase is normal and expected finding. This result was in agreement with Emam (2004) who noticed adirect relation ship between memory attrition and length of time that elapsed after exposure to certain educational event.The observed significant improvement in 'the studied nurses' knowledge and practice when exposed to an educational experience indicate that these nurses could readily benefit from it and in real need for such information which help to recall and momarization. The effect of the program was confirment through multi variate analysis that identified the program attendance as strong positive independent predictor of the knowledge and practice scores.This findings were in agreement with Masoud 
(2006), who concluded that nurses knowledge and practice improved immediately after exposure to the training program with decline 3 month later yet remaining higher than pre exposure to the educational program .This findings also was consistent with Rance \& Trent (2005), Huang et al., (2009), Marzouk, et al., (2012), Kanteel \& Attia (2013) \& El Emery et al., (2013).

According to the present study findings nurses qualification and years of experience did not have influence on the nurses' knowledge and practice scores improvement.This may attributed to this group of nurses was homogenous and there were a little difference between their sociodemographic data and the majority played the same role in gaining and integrating knowledge and practice .Also indicated that emergency educational program was beneficial to all nurses.this result was in agreement with study done by Kandeel \&attia (2013) who mentioned that nurses educational level did not have any influence on practice in the ICUs studies. This finding also was in constant with Emam, (2004), Gadallah et al., (2009) \& Taha \& Ali, (2013). However this result disagreed with Al-Khaled et al., (2011) who mentioned that higher education of the nurses was associated with better performance.

\section{Conclusion}

The educational program for nurses working in the emergency medical unit was successful in upgrading their knowledge and practice concerning diabetic crisis .Newly graduated nurses did not receive any orientation program about management of diabetic crisis before working in this unit.

\section{Recommendations}

In the light of the study findings, the following recommendations were suggested:

- Orientation program should be utilized for newly graduated nurses to improve their knowledge and practice along with continuous supervision and feedback.

- Nurses in these types of units should upgrading their knowledge and practice through frequent attending seminars, and conferences based on their needed assessment .

- Availability of library in emergency medical unit rich with illustrated booklet, periodical and internet .

- Periodic refreshing courses for these nurses concerning any emergency situation in this critical care units .

\section{References}

1. Ali Z., (2011) Health and Knowledge progress among Diabetic patients after implementation of nursing care program based on their profile , $\mathrm{J}$ Diabetes Metab.2:121.

2. Al-Khaled T., Zahran E., \& El soussi A., (2011): Nurses, related factors influencing the use of physical restrain in critical care units ,Journal of American Science :7(8) 21 http://www.american science .org.

3. Cannon M., Sprivulis P., \& Mccarthy J., (2001): Restraint practice in Australasion emergency departments Aust NZJ psychiat ry 35:464-467.

4. CDC, (2009): National diabetic fact sheet :general information and national estimates on diabetes in the United states .Retrieved February 24 from http://www:ed.gov.

5. Cherlene S., Pedrick R., Harland D., (2013): hyperglycemic Crises managingacute complications of diabetes National center of continuing Education,Inc.www.nursece.com.

6. El Emery S., Labeeb S., Marzouk S., \& Hussien A., (2013): An in-service training program about nursing care of children with poisoning at emergency unit ,Egyptian Nursing Journal June Vol.4 No.2 p11.

7. Emam E., Hassan S., \& Moghozy, D (2004): Effect of educational program of paramedicals knowledge and Attitude toward infection control in El-Minia city Hospital MSc thesis obestetric and Gynecology nursing ,Assuit university

8. Gadallah M., Ahmed E., Mohamed A., \& Abd El-Kareem H., (2009): Impact of Educational \& training program about chest physiotherapy for nurses working in emergency, intermediate and intensive care units at Assuit University children Hospital ,Assuit Med.J.vol.(33)No.(3) September

9. Ganam H., Mohamed Z., Mohamed A., \& Ahmed N., et al., (2011): Impact of in-service training program on operating room nurse for reducing incidence of infection ,first international nursing conference, Innovations in nursing education\&practice leading quality care Muscat -sultanate of Oman 28-29, November.

10. Global prevalence of Diabetes Estimates for the year (2000): \& projections for 2020 Diabetic care 5:1047-1053

11. Guilbert J., (1999): Educational Handbook for Health personnel $6^{\text {th }}$. Geneva: WHO publication ;No.35:260.

12. Hafez M., (2011): problems encountered among patients utilizing physical restraint in Monsoura University Hospital Master thesis ,faculty of nursing, Zagazig university . 
13. Huang H., Chuang Y., \& Chiang K., (2009): Nurses, physical restraint knowledge attitudes and practice the effectiveness of an in-service education program JNurs Res 17:241-248.

14. IDF, (2009)the world at aglane retrieved February 21,from http// www.merchmed,cus.

15. Kandeel N., \& Attia A., (2013): Physical restrains practice in adult intensive care units in Egypt .Nurs Health Sci,15.79-85.

16. Kaplow, R., \& Hardin, H., (2007), Critical care Nursing Synergy for optimal outcome ,Jone and Bartett publishers London p.519.

17. Kim, S., (2007): Burden of hospitalizationprimarily due to uncontrolled diabetes :implications of inadequate primary health in the United States Diabetes Care 30:1281-1282.

18. Kitabehi, A., et al., (2010): hyperglycemic crisis in adult patients with diabetes ,American Diabetes Association .

19. Mamun, K., Lim J., (2005): Use of physical restrains in nursing home current practice in Singapore Ann Acad Med Singapore 34:158162.

20. Marzouk S., El-dien H., Thabet R., \& Elzaher A., (2012): Impact of educational program about menarche on improving adolescents self concept at assuit Governorate, life science Journal Vol.10 No.1 .

21. Masoud E., (2006): The impact of educational and training program on the knowledge and performance of nursing practice in the hematology and emergency units at pediatric department of Assuit University Hospital.PhD thesis ,pediatric Nursing, Assuit University .

22. Mohamed N., \& Abedel Hammed (2012): Effectiveness of communication skills training program on improving burnout and self-esteem among nursing staff in psychiatric hospital at Assuit Governorate ,Med.Journal of Cairo University Vol.80 No.1 pp10-11.

23. Morton P., \& Fontaine D., (2013): Critical care Nursing $10^{\text {th }}$ ed. Aholistic approach,Lippincott Willaim \&Wilkins ,Newyork,pp.1004-1018.

24. National Center for Health Statistics, (2009): National hospital discharge and bulatory surgery data, Available from http://wwwedc.gov/nchs/about/major /hdasd/ahds.htm.Accessed January 24.

25. Neeraje K., (2003): textbook of nursing education 1ed. Gopsons Papers Ltd.,Jaypee Brothers Medical Publishers (p)Ltd 267-277.

26. Oermann M., Kardong-Edgren S., Odommaryon T., (2011): Effects of monthly practice on nursing students,CPR Psychomotor skill performance .Resuscitation 82,447-453.
27. Oskouie,F. Mehrdad, N., \& Ebrahimi, H., (2013): Mediating factors of coping process in parents of children with type 1 diabetes ,Journal of diabetes metabolic disorders 12:20 http//www.jdmd on line.com/content/12/20.

28. Rance K., Trent C., (2005): Profile of a primary care practice Asthma program improved patient outcomes in a high risk population $\mathrm{J}$ pediatric Care ,19(1):25-32.

29. Smeltzer, S., Bare B., \& Hinkie, J., Cheever K., (2008): Brunner \&Suddarth, $11^{\text {th }}$ ed.lippincott Willaim\&Wilkins ,Newyork,p.1415.

30. Taha N., \& Ali Z., (2013): Physical restrains in critical care units impact of atraining program on Nurses,knowledge and practice and on $\begin{array}{llll}\text { patients,outcomes,J Nurs Care 2:2 } & 135\end{array}$ http://dx.doi.

31. Urden L., stracy, K., \& Lough, M., (2012): Critical care nursing, diagnosis and management $7^{\text {th }}$ ed. Mosby ,Calforniapp.906-913.

32. White N., (2010): Diabetic Ketoacidosis in children .Endocrinol Metab Clin North Am;29:657-682.

33. Wolfsdorf J., Glaser, N., Sperling M., (2006): Diabetic ketoacidosis in infant,children and adolescents :aconsensus statement from the American Diabetes Association.Diabetic care ;29:1150-2259. 